\title{
O Financiamento de Campanhas Eleitorais sob a Ótica da Democracia
}

\author{
The Funding of Electoral Campaigns from the Perspective of Democracy
}

Luciana Ferreira

Luiz Magno Pinto Bastos Junior

Resumo: Este trabalho dedicou-se a avaliar, no contexto da reforma política no Brasil, os avanços que poderiam culminar no aperfeiçoamento do sistema político, o qual se apresenta fracassado quanto aos objetivos da democracia representativa. $\mathrm{O}$ foco da análise recaiu sobre a substituição do financiamento misto de campanhas eleitorais, esse considerado ponto de destaque na crise da representação política atual. O estudo bibliográfico pautou-se em obras especializadas, artigos científicos, matérias jornalísticas e entrevistas com experts publicadas em revistas especializadas acerca do tema em pauta. A análise identificou que a proibição das doações por empresas não garantirá o fortalecimento da relação entre representantes e eleitores.

Palavras-chave: Reforma Política. Democracia Representativa. Financiamento misto de campanhas eleitorais. Crise da representação política.

\begin{abstract}
This paper is dedicated to analyze, in the political reform's context in Brazil, the advances that could result in an improvement of the political system, which is now stated failed, considering the representative democracy's objectives. The analysis' focus remained upon the subject of the replacement of the mixed financing of election campaigns, considered an important point in the current political representation crisis. The bibliographical study is based on proficient works, scientific articles, newspapers' items and interviews with specialists published in magazines with specialized knowledge about the topic discussed. The analysis' conclusions was that the prohibition of the companies and firms' donations would not guarantee an expected result, like a strengthening of relationships between political representatives and voters.
\end{abstract}

Keywords: Political Reform. Representative Democracy. Mixed financing of election campaigns. Political representation crisis.

Artigo recebido em 21 dez. 2016 e aprovado em 24 dez. 2016. 


\section{Introdução}

A crise da representação democrática no Brasil é evidente. Os votos de protesto, as manifestações de rua e o distanciamento da sociedade das questões políticas, entre outros, refletem isso. Logo após as eleições é comum o eleitor não se lembrar em quem votou. Isso está diretamente relacionado ao pouco interesse dos cidadãos pela atividade política.

O sistema político, no geral, é alvo de duras críticas. Nesse ínterim, a reforma política no Brasil é tema recorrente no Congresso Nacional, revelando-se polêmica e com poucos consensos; geralmente é tratada de forma oportunista, eis que, quase sempre, as melhorias buscadas não refletem os anseios da sociedade quanto ao fortalecimento da representação política, refletem, na maioria das vezes, mudanças de cunho superficial, tendentes a fazer de conta que uma resposta foi dada à sociedade sobre determinado ponto crítico.

O financiamento misto de campanhas, apontado no contexto da reforma política como um dos fomentadores da crise de representatividade vivida no Brasil, é comumente associado a casos de corrupção, e foi alvo recente de ação direta de inconstitucionalidade, a qual julgou inconstitucional o financiamento de partidos e de campanhas eleitorais por empresas.

Os vícios identificados nesse elemento do sistema político levam os parlamentares, os estudiosos e a própria sociedade a aventar soluções para os problemas, sendo as mais comuns as propostas de abandono do atual modelo com vistas à adoção de outro, em tese, melhor. A justificativa deste estudo é a incerteza de que uma eventual substituição possa ser salutar à jovem democracia brasileira.

Desse modo, o estudo pautou-se em obras especializadas, artigos científicos, matérias jornalísticas e entrevistas com experts publicadas em revistas especializadas, objetivando concluir, sob o ponto de vista do fortalecimento da democracia representativa, se é justificável uma eventual substituição do modelo misto de campanhas eleitorais.

Para isso, cuidou-se, num primeiro momento, de fazer uma abordagem introdutória sobre a reforma política como consequência da crise na representação política, tendo sido apresentadas as principais modalidades de financiamento de campanhas eleitorais da atualidade, destacando-se seus pontos controvertidos. Num segundo momento tratou-se de explicitar a discussão que culminou na proibição das doações por empresas, abordan- 
do-se as pertinentes questões polêmicas, e chegando-se à conclusão de que restringir o poder econômico na política não contribui para a legitimidade da democracia representativa. Tal objetivo somente seria atingido com a adoção de mecanismos eficientes de regulação de gastos e doações e, principalmente, pela adoção de eficazes medidas que confiram ampla divulgação, publicidade e transparência às doações e gastos de partidos e candidatos.

\section{O Financiamento de Campanhas Eleitorais no Contexto da Reforma Política}

O que é Reforma Política? De forma bastante sintética, Aragão (2014) apresenta a definição de Reforma Política com base em especialistas, analistas, formadores de opinião, e lideranças políticas e sociais que "dizem que se trata de um conjunto de normas destinadas ao aperfeiçoamento do sistema político nacional.”.

A realização de uma verdadeira reforma política que promova esse aperfeiçoamento implica analisar, de forma responsável e ética, o funcionamento dos componentes do sistema político, para que as mudanças que venham a ser promovidas se revelem eficazes ao enfrentamento da crise institucional verificada na organização política e eleitoral. Não há soluções fáceis quando se tem como objetivo o aprimoramento da democracia representativa.

Nesse contexto, sendo o financiamento de campanhas eleitorais o elemento a ser analisado neste estudo, mostra-se conveniente abordar os variados aspectos críticos que o envolvem. Dessa forma, serão trazidas a lume questões como a inegável importância do dinheiro para a manutenção dos partidos políticos e para a realização das campanhas eleitorais; o excesso de gastos nas eleições; a influência abusiva do poder econômico no resultado eleitoral; o risco da estatização dos partidos como decorrência da adoção de um modelo exclusivamente público; a corrupção; a doação por pessoas físicas como forma de participação cívica do cidadão; o direito das empresas de influenciarem no debate público, e a regulação do dinheiro na política.

Exposta a problemática da reforma política no Brasil no que tange ao modelo de financiamento de campanhas eleitorais, passa-se, a seguir, a uma sintética exposição das principais modalidades desse elemento do sistema político. 


\subsection{Os Modelos de Financiamento: Misto, Exclusivamente Público e Exclusivamente Privado}

À luz de sua origem, o financiamento de campanhas eleitorais pode ser público, privado ou misto. No Brasil, atualmente, adota-se o modelo misto de financiamento de campanhas eleitorais, com contribuição tanto do Poder Público quanto do setor privado (GOMES, 2010, p. 268).

No que tange ao componente público do financiamento misto, a Lei dos Partidos Políticos (Lei n⿳ 9.096/95) define o Fundo Partidário como o seu provedor. Sobre a constituição do Fundo Partidário, dispõe o artigo 38 da referida lei que o Fundo é constituído por dotações orçamentárias da União, multas, penalidades pecuniárias, doações de pessoas físicas e jurídicas e outros recursos financeiros que lhes forem atribuídos por lei (BRASIL, 1995).

Com relação ao componente privado quanto a doações por pessoas físicas, o artigo 23 da Lei das Eleições permite que pessoas físicas façam doações em dinheiro ou estimáveis em dinheiro para campanhas eleitorais. As doações em dinheiro ficam limitadas a dez por cento dos rendimentos brutos auferidos no ano anterior à eleição (artigo $23, \$ 1^{\text {º) }}$.

Ainda com relação ao componente privado, eram permitidas, até a edição da Lei no 13.165/2015 (minirreforma eleitoral), as doações e contribuições de pessoas jurídicas para campanhas eleitorais (art. 24, da Lei no 9.504/97, na parte em que autorizava tais doações a contrário sensu, parágrafo único do mesmo dispositivo, e art. 81, caput e $\$ 1^{\circ}$ ). Importa registrar que essas ficavam limitadas a doação de, no máximo, 2\% (dois por cento) do faturamento bruto do ano anterior à eleição (BRASIL, 1997).

Sobre o surgimento do financiamento exclusivamente público, Santano (2015) esclarece que se buscava afastar que partidos e candidatos dependessem economicamente de grupo cujos interesses privados fossem de encontro aos interesses democráticos de um governo representativo.

Consoante os ensinamentos do cientista político uruguaio Rial (2005), na maioria das legislações atuais da América Latina, as agremiações políticas revelam-se como organizações dobradiças; isto é, os partidos políticos situam-se tanto no campo público como no privado. Assim sendo, é possível que os partidos recebam financiamento público, eis que são "associações privadas que cumprem funções públicas ou de interesse geral". 
Sobre quem deve ter o direito de receber o financiamento público e como ele deve ser distribuído entre aqueles que são elegíveis, Ohman (2015) assevera que há duas questões relevantes quando se cuida desse aspecto do financiamento público: o limiar de elegibilidade e os critérios de alocação.

No Brasil, o artigo 41 da Lei dos Partidos Políticos supracitada dispõe que 95\% dos valores do Fundo Partidário devem ser distribuídos para a legenda, na proporção dos votos obtidos na última eleição geral para a Câmara dos Deputados. Os 5\% restantes devem ser divididos em partes iguais entre todos os partidos que tenham seus estatutos registrados no TSE.

Sobre a modalidade de financiamento exclusivamente privada, Tonial e Oliveira (2014) disciplinam que é composta pela contribuição dos filiados do partido, doações de pessoas físicas ou jurídicas e, ainda, recursos do próprio candidato à sua campanha eleitoral. Não há, dessa forma, nenhuma parcela pública de contribuição.

Rubio (2005) ensina, por sua vez, que esse modelo revelou-se durante muito tempo como única fonte de receita para partidos e candidatos. Essa situação perdurou até a metade do século XX, quando os riscos oriundos da permissão de que a política fosse financiada com fundos originados de setores economicamente fortes passou a ser enfatizado por uma nova corrente de opinião. De acordo com essa corrente, os representantes políticos tornar-se-iam dependentes do poder econômico, e disso resultaria um maior comprometimento desses representantes com os interesses particulares em detrimento do interesse público.

Apresentadas as modalidades de financiamento misto, exclusivamente público e privado, abordar-se-á, na sequência, os principais pontos controvertidos dessas modalidades.

\subsection{Pontos Controvertidos dos Modelos de Financiamento}

Todas as modalidades de financiamento (mista, exclusivamente privada ou exclusivamente pública) possuem desvantagens. Iniciando pelos modelos misto e exclusivamente privado, Rubio (2005) assevera que:

Sem dúvida, o financiamento privado tem gerado mais críticas que elogios. Embora o aporte de recursos aos partidos por parte de cidadãos e empresas possa ser visto como uma forma de participação 
política, ou mesmo como uma forma de expressão da própria ideologia, objeta-se que pode conduzir a uma "colonização" das estruturas estatais por parte de grupos privados economicamente poderosos. Quando isso ocorre, afeta-se a essência mesma das democracias representativas, pois os dirigentes políticos, congressistas, presidentes e ministros podem deixar de atuar em prol do bem comum e transformar-se em agentes de alguns grupos de interesse.

Fazer a opção pelo modelo que melhor atenderia aos anseios da sociedade brasileira quanto à solução das mazelas verificadas atualmente revela-se atividade complexa. Nas palavras de Santano (2015, p. 66): “Os problemas nesta seara costumam ser cíclicos e atualmente há um consenso de que estes problemas não podem ser resolvidos definitivamente, ainda mais considerando a velocidade das modificações tanto dos partidos quanto da sociedade em geral.".

Sobre os problemas verificados no modelo de financiamento misto, convém registrar que, não obstante haver inconteste rejeição à doação de recursos de pessoas naturais às campanhas, as críticas, na sua maioria, referem-se aos limites definidos pelo legislador. Os amplos limites podem ensejar campanhas economicamente desiguais, o que pode levar a uma desigualdade política, conforme argumentos constantes da ADI (Ação Direta de Inconstitucionalidade) $4650^{1}$ (SUPREMO TRIBUNAL FEDERAL, 2015a):

Quanto às pessoas naturais, não se afirma que a admissão das suas doações de campanha seja um mal, sob a perspectiva constitucional. Tais doações podem ser concebidas como uma forma de participação cívica do cidadão, que se empenha em promover na esfera pública os seus ideais e preferências políticas. Eleições nas quais as campanhas sejam financiadas por uma grande quantidade de pequenas doações de eleitores podem ser vistas como um momento virtuoso

\footnotetext{
${ }^{1}$ Dispositivos legais questionados: artigo 23, \ $1^{\circ}$, incisos I e II; artigo 24, na parte na qual autoriza, a contrário sensu, a doação por pessoas jurídicas a campanhas eleitorais; e o artigo 81, caput e $\int 1^{\circ}$ da Lei n⿳o 9.504, de 30 de setembro de 1997, e o artigo 31, na parte na qual autoriza, a contrário sensu, a realização de doações por pessoas jurídicas a partidos políticos; artigo 38, inciso III, das expressões "ou pessoa jurídica", e artigo 39, caput, e \ 5ํ, da expressão "e jurídicas", da Lei nº 9.096, de 19 de setembro de 1995. Consultar ADI 4.650 disponível em: <http://stf.jusbrasil.com.br/jurisprudencia/23086639/acao-direta-de-inconstitucionalidade-adi-4650-df-stf $>$
} 
de mobilização cívica. Contudo, é fundamental limitar ditas doações, para não permitir que a desigualdade econômica, disseminada em nossa sociedade, se converta também, automaticamente, em desigualdade política. E os limites estabelecidos pelo legislador eleitoral não mantêm relação minimamente razoável com o referido objetivo.

No que tange à permissão de financiamento por empresas (modelos misto e exclusivamente privado), consoante Santano (2015), permanentemente são questionados a corrupção e o forte condicionante sobre a agenda política dos grupos de pressão economicamente destacados, que, em tese, seriam eliminados por um eventual modelo de financiamento público.

No tocante à corrupção, pesquisa realizada pelo Instituto Datafolha por encomenda do Conselho Federal da Ordem dos Advogados do Brasil revelou que a maioria da população brasileira (79\%) acredita que seja estimulada pelo financiamento por empresas. Nesse contexto, manifestou-se o presidente do Conselho Federal da OAB, Coêlho (2015): "as suspeitas sobre a origem do dinheiro que abasteceu campanhas, como apontado em delações premiadas da operação "lava jato" - que investiga corrupção na Petrobras -, reforçam a necessidade de mudanças no sistema eleitoral brasileiro.".

Tratando-se do problema da corrupção, Santano (2014) aponta que ao avaliá-la não se deve cair na tentação de pretender eliminá-la; isso porque é utópico pensar que ela poderá ser extinta em definitivo. Sempre haverá corrupção, independente da conjuntura, pois "a corrupção se dá basicamente porque o indivíduo decidiu praticar uma conduta corrupta”. Inexiste um controle que seja eficaz ao extremo e impeça que um sujeito pratique a corrupção. No contexto do financiamento da política, a autora pontua (2014, p. 180):

O que se deve ter em mente é que o financiamento público não produz corrupção, mas também não a impede. Ocorre o mesmo com o financiamento privado, que sim gera corrupção no lugar de reduzi-la, se não vem acompanhada de medidas que reduzam o seu impacto. A saída é o financiamento misto, mas se não está bem nivelado entre um e outro, os efeitos colaterais podem ser de significativa importância. 
Convém ainda reiterar a existência de exemplo histórico de que a mudança no modelo, conforme proposta pelo presidente do Conselho Federal da $\mathrm{OAB}$, não logra êxito quando se pretende combater a corrupção. Cumpre relembrar que o sistema misto de financiamento de campanhas no Brasil teve como um dos principais motivos "o escândalo Collor-PC [que] revelou que as empresas tinham se tornado a principal fonte de financiamento das disputas eleitorais durante os anos 1980, não obstante uma legislação que explicitamente proibia doações de empresas" (SPECK, 2015b, p. 51-53).

Entre as críticas ao modelo, ainda merece destaque o excesso nos gastos de campanha. A cada eleição, as campanhas se mostram mais caras. Os gastos se superam. Tal fato pode ser verificado nos dados apresentados pelo Jornal O Estado de S. Paulo, na edição de 1 de dezembro de 2014:

A campanha eleitoral deste ano [2014] apresentou um custo total de $\mathrm{R} \$ 5,1$ bilhões, segundo levantamento feito nas despesas declaradas ao Tribunal Superior Eleitoral. Em 2014, este foi o total gasto da campanha de todos os candidatos a deputado, senador, governador e presidente. Se comparado com o financiamento eleitoral total calculado pela ONG Transparência Brasil desde 2002, trata-se do maior valor da série já corrigido pela inflação. Naquele ano, foram gastos $\mathrm{R} \$ 792$ milhões.

Acerca do antídoto para o gastos excessivos de campanha eleitoral, o Ministro Teori Zavascki (2014), em seu voto-vista na ADI 4650, asseverou que não se trata de declarar a inconstitucionalidade das fontes de financiamento. Para o Ministro, a eliminação formal dos recursos provavelmente seria imediatamente substituída por suplementação informal e ilegítima.

Por outro lado, acerca dos problemas advindos de um sistema de financiamento integralmente estatal, Rubio (2005) afirma que o governo em cumprimento de mandato pode valer-se desse expediente para criar obstáculos aos partidos de oposição na corrida eleitoral. Ou seja, esse sistema pode dar margem a manobras de exclusão. O governo, com o objetivo de dificultar a atuação política dos grupos de oposição, pode criar obstáculos para sua atuação política: 
Se a lei restringe o financiamento político, por exemplo, aos partidos que tenham representação parlamentar e simultaneamente proíbe os aportes privados, o resultado será o congelamento do sistema partidário. Ainda que a lei estabeleça critérios objetivos e amplos para a dotação de fundos, o governo poderá dificultar o acesso dos recursos à oposição por vias burocráticas indiretas. Nesses casos, o financiamento privado pode funcionar como elemento propiciador da competitividade eleitoral e política (RUBIO, 2005).

No tocante ao financiamento público em países com índices de pobreza elevados e população insatisfeita relativamente às necessidades básicas, a cientista política Pironi (2009) questiona o uso de recursos públicos para financiar campanhas eleitorais:

Como podemos esperar que apenas o governo financie campanhas eleitorais enquanto pessoas passam fome? Seria interessante haver nesse ponto ajuda maior do financiamento privado para poupar dinheiro público destinado a projetos sociais. O ponto positivo do financiamento público é o comprometimento com os partidos, principalmente os menores que não arrecadam tanto dinheiro.

De acordo com Rubio (2005), duas outras questões são relevantes quando se quer destacar pontos negativos do financiamento público:

[...] se o grosso dos gastos dos partidos é custeado com recursos públicos produz-se uma relação de dependência com o Estado, uma espécie de "estatização" dos partidos. Essa dependência se torna politicamente mais perigosa para o livre jogo democrático quando a administração dos fundos de financiamento público está nas mãos do governo e não de uma entidade independente. Outra questão relevante é o distanciamento dos partidos em relação à população, aprofundando a crise de confiança que os afeta.

Apresentados os modelos de financiamentos e destacados os pontos controvertidos das três modalidades tratadas, mostra-se conveniente abordar pontos específicos da discussão que culminou na proibição da doação por pessoas jurídicas, bem como trazer à baila eventuais medidas que poderiam ser adotadas, para fins de aperfeiçoamento do modelo de financiamento de campanhas eleitorais. 


\section{O Financiamento de Campanhas Eleitorais: a Discussão noSTF, a Minirreforma Eleitoral e a Necessária Regulação}

Verificou-se anteriormente que a sociedade não se vê representada pela classe política. Há um verdadeiro distanciamento entre esses dois polos, resultante parcialmente da influência desmedida do poder econômico no poder político.

Diante desse cenário, chegou ao Supremo Tribunal Federal (STF) a ADI 4650, proposta pela OAB (Ordem dos Advogados do Brasil), contestando dispositivos da Lei das Eleições (artigos 23, parágrafo 1ํㅜㄴ incisos I e II; 24; e 81, caput e parágrafo 1ํㅓㅇ da Lei no 9.504/1997) e da Lei dos Partidos Políticos (artigos 31, 38, inciso III; e 39, caput e parágrafo 5을 da Lei no 9.096/1995).

Em 17 de setembro de 2015, quase dois anos após o início do julgamento, o STF declarou a inconstitucionalidade do financiamento de campanhas eleitorais por empresas. Dos onze Ministros do STF, oito manifestaram-se a favor da inconstitucionalidade do financiamento eleitoral por empresas, e os três demais votaram a favor da doação por empresas a campanhas (GALLI, 2015).

Poucos dias antes, em 10 de setembro de 2015, por sua vez, a Câmara dos Deputados havia aprovado o Projeto de Lei no 5.735/2013, que admitia a doação por empresas a partidos políticos com limites nominais. No entanto, a Presidenta Dilma Rousseff, ao sancionar a lei aprovada pelo Congresso Nacional, vetou o trecho que permitia a doação de empresas a campanhas eleitorais.

Da decisão do STF e do veto da Presidenta originaram-se inúmeras polêmicas que merecem ser trazidas à baila, tendo em vista que o objetivo que se busca atingir é concluir se o afastamento das doações de pessoas jurídicas, por si só, levaria ao aperfeiçoamento do sistema político.

\subsection{O STF e o Congresso Nacional: Proibição Legal ou Permissão com Limites?}

Munida de intuito moralizador, segundo Neisser (2013), a OAB, na ADI 4650, defendeu a tese que busca impor a solução mais simples: "veda-se totalmente a doação eleitoral ou partidária realizada por empresas". Quanto ao resultado, adverte: "é de se reconhecer que a proibição logrará 
evitar o resultado previsto na norma com, no máximo, a mesma eficácia que qualquer proibição legal o faz".

$\mathrm{Na}$ ADI 4650 a OAB sustentou a inconstitucionalidade do financiamento de campanhas eleitorais por pessoas jurídicas, pediu a modulação dos efeitos da decisão para que o Congresso sanasse as lacunas eventualmente decorrentes de uma decisão favorável, bem como a fixação de um valor máximo de contribuição por pessoa física. Conforme noticiado no informativo do STF, sustentou a Ordem dos Advogados do Brasil:

O presidente do Conselho Federal da OAB, Marcus Vinicius Furtado Coelho, iniciou a defesa da ADI com o parágrafo único do artigo $1^{\varrho}$ da Constituição Federal, segundo o qual "todo o poder emana do povo, que o exerce por meio de representantes eleitos ou diretamente". Para ele, empresa não se enquadra no conceito de povo, "fonte titular de todo o poder". Empresa, argumentou, é fato jurídico, atividade econômica. O empresário, como indivíduo, pode participar do processo eleitoral, não a empresa.

Furtado Coelho afirmou que a legislação que regula o financiamento de campanhas no Brasil cria injustificada discriminação. Se um sindicato, por exemplo, não pode participar do financiamento por receber favores públicos, a empresa, beneficiária de tratamento tributário especial, não poderia fazê-lo. Argumentou, ainda, que a CF define as pessoas jurídicas de direito privado que podem participar da vida política: os partidos políticos, intermediários entre o cidadão e o exercício do poder.

O representante da $\mathrm{OAB}$ sustentou que "na hora do voto, todos os brasileiros devem igualar-se e não deve haver privilégio para o poder econômico, para quem o destino já delegou uma melhor sorte". Ele concluiu pedindo que seja definido um valor máximo de contribuição e que o STF, se acolher o pedido, module os efeitos da decisão para que o Congresso Nacional seja instado a legislar sobre as lacunas decorrentes da eventual declaração de inconstitucionalidade.

Quanto ao pedido de declaração de inconstitucionalidade, convém ressaltar a polêmica que daí decorreu. Dada a inexistência de vedação constitucional expressa às doações de pessoas jurídicas a campanhas eleitorais, pesaram sobre os Ministros do STF duras críticas durante o julgamento da referida ADI. A exemplo disso, Streck: 
[...] como lido com a Constituição e sou obrigado a defendê-la, tenho de me perguntar: a Constituição estabelece um (outro) modelo de financiamento de campanhas eleitorais? É assim tão fácil apontar onde está a parametricidade constitucional que sustenta as afirmações dos votos dos quatro ministros (relator e mais três) que votaram por essa inconstitucionalidade?

$[\cdots]$

Não preciso pesquisar muito sobre a tal falta de parametricidade. Para tanto, valho-me dos exatos termos da declaração de um dos quatro ministros do STF que já votaram na ADI 4.650, o ministro Roberto Barroso: "Em tese, não considero inconstitucional em toda e qualquer hipótese a doação [a campanhas eleitorais] por empresa". $[\ldots]$

Ele [ministro Roberto Barroso] votou a favor [da ADI 4.650-DF]. $[\ldots]$

Podem as doações ser ruins, inadequadas, aéticas, imorais, etc. etc. (e mais um etc.!). E o são. Mas, a pergunta que a Suprema Corte de terrae brasilis (e não a dos Isteites) deve responder é tão-somente essa: são elas, as doações, inconstitucionais? Podem ser ruins, mas... inconstitucionais? Aliás, as palavras não são minhas, são do próprio ministro Barroso, que-não-considera-inconstitucional-em-toda-e-qualquer-hipótese a doação a campanhas eleitorais por empresa. Vejam: em-toda-e-qualquer-hipótese.

As instituições brasileiras viveriam um quadro de "inconstitucionalidade permanente", segundo a OAB, pois os dispositivos legais impugnados na ADI 4650, supostamente, violariam desde sempre os princípios democrático e republicano. Teles Filho (2014) rebate aludidos argumentos, afirmando que: "As pessoas físicas e jurídicas não são iguais perante a política", pois as empresas não são consideradas cidadãs, não possuindo direito a voto. $\mathrm{Na}$ democracia representativa, a igualdade na contagem dos votos é essencial, já a igualdade de influência não é:

Enquanto o direito de voto refere-se à constituição dos representantes do povo, a influência refere-se ao debate público, relacionado ao conceito de democracia discursiva. Por isso, o fato de a influência distribuir-se de maneira diferente na sociedade, não desvirtua per se o caráter democrático da representação (TELES FILHO, 2014). 
Consoante Celso de Mello (SUPREMO TRIBUNAL FEDERAL, 2015b, p. 1), Decano do STF, “a Lei Maior não veda a influência, o que a lei fundamental veda é exercício abusivo do poder econômico." O Ministro entende que os interesses das pessoas jurídicas de direito privado são legítimos, e que sua veiculação deve ser amparada e protegida pelo sistema jurídico. Cabe ao Ministério Público, aos outros partidos políticos e aos candidatos realizar um controle efetivo dessas doações, que devem ser feitas às claras.

No que tange à tese de que as doações de recursos por pessoas jurídicas às campanhas caracterizam violação aos princípios democrático e republicano [tese que, além de ser aventada pela OAB na ADI 4650, é também amplamente aceita pela sociedade em geral], Teles Filho (2014) argumenta que se encontra fundamentada numa confusão entre direito de voto e influência. $\mathrm{O}$ autor aduz que feita a necessária distinção entre direito de voto e influência, o princípio da igualdade do voto não se revela suficiente para afastar as doações privadas do financiamento das campanhas.

Outro ponto polêmico no julgamento da ADI 4.650 foi o estratégico pedido de vistas do Ministro Gilmar Mendes, que interrompeu o julgamento da ação por um ano e cinco meses. Mendes devolveu o processo exatamente um dia após a Câmara dos Deputados aprovar as doações por empresa. O ministro recebeu muitos ataques, principalmente por meio eletrônico (a situação gerou protestos nas redes sociais como o apelo: "Devolve, Gilmar") e de pressões de parlamentares, que cobravam celeridade: É chato esse papel que eu fiz de pedir vista dos autos, mas eu o fiz com grande consciência", desabafou. E continuou: "Hoje, quando formos discutir sobre isso, saberemos muito mais sobre questões importantes, como o que vem sendo exposto na [operação] 'lava jato', por exemplo.

Outra crítica contundente que atingiu o STF referiu-se à interferência do Judiciário em questões de competência do Legislativo, eis que a instituição com competência constitucional para a edição de leis é o Congresso Nacional. Nesse sentido, Henrique Eduardo Alves, presidente da Câmara dos Deputados (2013-2015), à época do ajuizamento da ação, defendeu que "a reforma política é uma questão privativa do Poder Legislativo. O Judiciário é importante na interpretação das leis, mas quem tem legitimidade de fazer a lei [...] é o Poder Legislativo.”. 
Contrapondo-se ao argumento de Alves, e minimizando o problema, o relator da ADI, Ministro Luiz Fux, defendeu a competência do STF, asseverando que a Corte tem novo entendimento em questões como essa:

em vez de simplesmente declarar a inconstitucionalidade da regra, o tribunal estabelece um prazo para que o Congresso elabore uma legislação, conforme os parâmetros constitucionais.

No financiamento de campanha, nesse julgamento, nós exortamos o Congresso a elaborar um novo modelo institucional, fazendo uma reforma que evite a captura do poder político pelo poder econômico.

Corroborando o entendimento de Henrique Alves, o Ministro Gilmar Mendes afirmou que o Congresso deve ser o foro da reforma política. De acordo com o Ministro, apesar da urgência, o STF não pode fazer a reforma, pois cabe ao Legislativo promover as mudanças. Em audiência no Senado Federal, o ministro avaliou: "Muitas vezes, nós, do próprio Judiciário, nos animamos a participar do processo de construção e nem sempre - vamos assumir isso - somos felizes nas intervenções.”.

No âmbito do Poder Legislativo, o Congresso Nacional aprovou o Projeto de Lei no 5.735/2013. Isso ocorreu em 9 de setembro de 2015, quando o texto do Senado para o projeto de lei foi parcialmente aprovado pelo Plenário da Câmara dos Deputados, o qual, além de manter as doações de pessoas jurídicas (exclusivamente a partidos), estabeleceu limites a essas doações:

Além do limite de doação na lei atual, de até $2 \%$ do faturamento bruto da empresa no ano anterior à eleição, o texto prevê que as doações totais poderão ser de até $\mathrm{R} \$ 20$ milhões e aquelas feitas a um mesmo partido não poderão ultrapassar $0,5 \%$ desse faturamento. Todos os limites precisam ser seguidos ao mesmo tempo.

Acima desses limites, a empresa será multada em cinco vezes a quantia em excesso e estará sujeita à proibição de participar de licitações públicas e de celebrar contratos com o poder público por cinco anos por determinação da Justiça eleitoral.

Anteriormente à aprovação do referido PL no 5735/2013, a Câmara dos Deputados, em 12 de agosto de 2015, havia aprovado proposta de emenda constitucional (PEC n 182/2007), que também permitia que as empresas fizessem doações a partidos políticos. Vale consignar que o texto 
dessa proposta foi encaminhado ao Senado Federal, mas não foi analisado. Falcão e Santano (2015), debatendo sobre a PEC 182/2007, destacaram que a adoção de limites nominais para doações não foi abordado, "deixando vazia esta importante discussão", e que "a adoção de limites nominais ou uma combinação entre os dois tipos [sendo que o segundo tipo são os limites baseados em porcentagens do faturamento atingido no ano anterior à eleição pela pessoa jurídica] de balizas é medida salutar, evitando-se assim o abuso de poder econômico nas eleições.".

Cumpre registrar, no entanto, que a Presidenta da República vetou os dispositivos da Lei no 13.165/2015 (minirreforma eleitoral) que permitiam as doações de empresas a partidos e estabeleciam os limites nominais. Dessa feita, de acordo com a Lei da Minirreforma Eleitoral, o que temos hoje é apenas o financiamento por pessoa física com limite estabelecido em 10\% da renda bruta anual. O veto da Presidenta foi apresentado sob as seguintes razões:

A possibilidade de doações e contribuições por pessoas jurídicas a partidos políticos e campanhas eleitorais, que seriam regulamentadas por esses dispositivos, confrontaria a igualdade política e os princípios republicano e democrático, como decidiu o Supremo Tribunal Federal - STF em sede de Ação Direita de Inconstitucionalidade (ADI 4650/DF), proposta pelo Conselho Federal da Ordem dos Advogados do Brasil - CFOAB. O STF determinou, inclusive, que a execução dessa decisão 'aplica-se às eleições de 2016 e seguintes, a partir da Sessão de Julgamento, independentemente da publicação do acórdão', conforme ata da 29a sessão extraordinária de 17 de setembro de 2015. (BRASIL, 2015).

Falcão e Santano, defendendo a imposição de limites nominais para doações, declaram: "os atuais limites, com base no faturamento a título de Imposto de Renda, dão muita força às pessoas jurídicas e físicas mais abastadas. Deve-se ressaltar que estes limites devem ser adequados à realidade brasileira, pois o arbitramento de valores irrisórios será seguramente ignorado.".

Dessa forma, a imposição de limites nominais às doações conceberiam maior equilíbrio às campanhas tendo em vista a extensa variedade entre dois por cento $(2 \%)$ do faturamento bruto de uma padaria de bairro, e dois por cento $(2 \%)$ do faturamento bruto de uma empreiteira com atuação em todo o território nacional. 


\subsection{A Necessária Regulação do Financiamento de Campanhas Eleitorais}

Muitos dos problemas atribuídos à doação de pessoas jurídicas às campanhas eleitorais existem realmente e, sem dúvidas, eles interferem na equalização da representação política. Afastar a influência do poder econômico da disputa eleitoral e, posteriormente, do exercício do poder, não é tarefa fácil, disciplina Neisser (2015). Mostra a experiência que o ingresso ilícito de recursos privados nas campanhas eleitorais não pode ser definitivamente afastado sequer pelo financiamento exclusivamente público. Segundo o autor, "O dinheiro atua como a água, sempre em busca de um canal de escoamento para dentro do sistema político.”.

Além disso, não se pode ignorar o fato de que as atividades de uma campanha eleitoral, por mais simples que sejam, como a impressão de um panfleto, por exemplo, demandam o despendimento de recursos financeiros. Conforme observa Guedes (2014 b), no sistema capitalista "O dinheiro fala, o dinheiro importa, o dinheiro paga (compra) eleições - money talks, money matters, money buys elections.". Nesse contexto, quando partidos, candidatos, grupos e o público em geral pretendem empreender a defesa ou o apoio de seus projetos, precisam antes ser capazes de alocar recursos e dinheiro para esses projetos.

A nossa matriz constitucional impõe que o exercício da democracia seja feito por intermédio dos partidos políticos e deve-se levar em consideração que os recursos financeiros são vitais aos partidos e às eleições. Nesse sentido, o voto-vista do Ministro Teori Zavascki na ADI 4.650 (2015):

Se é certo afirmar - e esse é o aspecto salientado na presente demanda - que o poder econômico pode interferir negativamente no sistema democrático, favorecendo a corrupção eleitoral e outras formas de abuso, também é certo que não se pode imaginar um sistema democrático de qualidade sem partidos políticos fortes e atuantes, especialmente em campanhas eleitorais, o que, evidentemente, pressupõe a disponibilidade de recursos financeiros expressivos. E, sob esse ângulo, os recursos financeiros contribuem positivamente para a existência do que se poderia chamar de democracia sustentável, com partidos políticos em condições de viabilizar o sadio proselitismo político, a difusão de doutrinas e de ideários, de propostas administrativas e assim por diante. 
Nesse sentido, Ferreira Filho (2012) adverte sobre a impossibilidade de os partidos políticos suportarem o alto custo das campanhas eleitorais se não puderem contar com doações. As campanhas eleitorais hodiernas valem-se dos meios de comunicação audiovisual (a televisão é o principal deles), e, em que pese não haver custos referentes à transmissão dos programas, pois a legislação brasileira garante a sua gratuidade, o custo da produção é elevadíssimo. Somam-se a isso os altos honorários dos profissionais (técnicos e peritos) necessários ao marketing político e, ainda, a realização de pesquisas eleitorais.

Em estudo intitulado "Reagir a escândalos ou perseguir ideais? A regulação do financiamento político no Brasil”, Speck (2015a) faz o seguinte questionamento: "a possibilidade de influenciar a política por meio de doações não introduziria a desigualdade pela porta dos fundos, destruindo o princípio do sufrágio igual para todos os cidadãos, uma das conquistas fundamentais da democracia moderna?". Referido autor admite que o quadro de desigualdades sociais do Brasil é um dos maiores do mundo, e que, em razão disso, o financiamento privado sem limites tem muito peso na questão da distorção na igualdade da representação.

Sobre esse aspecto, importa trazer à baila a necessidade de redução da quantidade máxima do valor a ser doado por pessoas físicas e jurídicas, conforme sugere Samuels (2003): "A lei deveria determinar a quantia-limite de dinheiro que cada pessoa ou empresa poderia doar por ano (...). Dever-se-ia determinar também a quantia máxima que uma pessoa poderia doar a um único candidato por ano.”.

Posicionando-se contrariamente à negativa do direito de doação pelas empresas, mas também entendendo ser necessário que os gastos e doações de campanhas eleitorais sofram regulação, Teles Fillho (2014) assevera que o parâmetro da regulação dos gastos e doações de campanhas eleitorais não deve ser a impossibilidade de participação das empresas, mas sim "o direito do cidadão de se informar para decidir e o direito dos partidos políticos de dar 'caráter nacional' às suas mensagens (artigo 5, IV, e XIV, e artigo 17, I, da Constituição)”.

Sobre a regulação dos gastos de campanhas, convém registrar que Lei no 13.165/2015 estabeleceu novas regras relativas aos limites de gastos nas campanhas de candidatos e partidos políticos. Já valendo para as eleições de 2016, esses limites de gastos, inclusive o teto máximo das despesas dos candidatos a prefeitos e vereadores, foram estabelecidos pelo TSE, ten- 
do sido fixados com base em montantes das eleições anteriores e critérios estabelecidos na Lei no $13.165 / 2015$.

A referida novidade representou um avanço, eis que, antes da minirreforma, tinha-se que o teto máximo dos gastos era determinado pelos próprios candidatos. A Justiça Eleitoral, por ocasião do registro de candidatura era apenas informada sobre o limite.

Com relação aos limites nas doações, especificamente acerca de limites nominais, Neisser (2013) disciplina que a imposição de um teto fixo, válido para uns e outros, que permitiria a todos a participação na atividade política, mas limitaria a influência individual a tal patamar, seria mais salutar do que vedar doações de empresas. Paralelamente a isso, segundo o autor, ao mesmo tempo, a fim de mitigar os efeitos do poder econômico, o financiamento público buscaria reduzir as discrepâncias de exposição entre as diferentes propostas políticas.

Sobre o bom funcionamento do sistema de financiamento da política que fundamental para o desenvolvimento institucional e democrático do país, Falcão e Santano (2015) observam:

Deve-se encontrar um ponto de confluência entre a liberdade, a igualdade e a transparência, pois na democracia todos têm o direito de participar da forma como entendem melhor, estando esta participação pautada por critérios que não desequilibrem as condições dos candidatos - evitando-se, assim, a dominação do poder econômico no resultado das urnas - bem como possibilitando aos eleitores uma melhor decisão do voto, a partir de informações sobre quem está financiando uma dada força política. Somente assim poderemos avançar na direção de uma democracia mais robusta.

$\mathrm{Na}$ democracia representativa todos devem ter o direito de participar em condições equitativas e a imposição de limites nas doações e gastos muito contribui para isso. Todavia, importa salientar que, além de regular essas doações e gastos, se faz necessário atuar com transparência na sua divulgação. Nessa esteira, verifica-se a necessidade de adoção de mecanismos de divulgações seguros e céleres. Acerca dessa ideia, o Ministro Dias Toffoli manifestou-se com relação à adoção da prestação de contas on line para candidatos: 
Temos essa experiência do México com relação à prestação de contas online, que também pretendemos implementar no Brasil, para termos a máxima transparência. Vamos colocar na resolução das campanhas eleitorais do ano que vem que, em 72 horas, ou seja, em até três dias, deverá estar na internet toda a movimentação financeira dos partidos e dos candidatos. Essa é uma boa prática que estamos trazendo para o Brasil.

De acordo com Neisser (2013), tapar o sol com a peneira, como aponta o dito popular, não o torna menos luminoso. Mais madura é a solução de uma sociedade que reconhece a existência do problema e sua complexidade; estruturando regras de transparência e controle que permitam ao menos minimizar os seus efeitos deletérios, ao mesmo tempo em que incentiva a participação política de todos os seus atores com recursos do orçamento público.

Kanaan (2012) defende que durante a campanha seja dada maior publicidade dos recursos arrecadados e gastos efetuados, maior publicidade quanto aos doadores e beneficiários também. Tais ações conceberiam maior efetividade à fiscalização realizada pelo Ministério Público Eleitoral, Justiça Eleitoral, adversários e sociedade civil.

Por fim, Rubio (2005) afirma que não há fórmulas universais quando se cuida dessa regulação do dinheiro na política. A autora aduz que o mais importante é divulgar, de forma completa e oportuna, a origem e o destino dos fundos que a financiam. Isso é mais importante do que estabelecer limites e restrições cujo controle e aplicação sejam difíceis de atingir. É necessário que o cidadão saiba quem está por trás de cada candidato, pois isso possibilita o "voto informado". Divulgar a origem e o destino dos fundos que financiam a política também é útil para incentivar os partidos a se controlarem reciprocamente, além de estimulá-los a ajustar sua conduta aos parâmetros legais e às exigências da opinião pública.

\section{Considerações Finais}

Cuidou-se de apresentar o conceito de reforma política, destacando-se que, em teoria, consiste no aperfeiçoamento do sistema político por intermédio de alterações legislativas pertinentes. Viu-se que, no Brasil, a reforma política é tema recorrente e polêmico, já que os consensos são raros. 
No Brasil, restou evidenciado que a representação política é abalada em razão dos escândalos provenientes do financiamento das campanhas. Diretamente, esses casos de corrupção influenciam de maneira negativa a relação entre representantes e representados. Em decorrência disso, apressam-se os interessados, que podem ser os partidos políticos, os estudiosos do tema, a própria sociedade, a defenderem, geralmente, a substituição do modelo vigente.

Nessa esteira, apresentou-se brevemente cada um dos principais modelos conhecidos. Ao componente privado, as regulações da Lei das Eleições (Lei n 9.504/1997). Na sequência, passou-se a analisar os pontos controvertidos dos modelos apresentados.

Quanto ao financiamento misto de campanhas eleitorais com a participação de recursos de pessoas jurídicas, não obstante ter sido vedado inicialmente pelo Supremo Tribunal Federal em razão de seu confronto com a igualdade política e ofensa aos princípios democrático e republicano, e, posteriormente, pelo veto da Presidenta da República aos dispositivos da Lei no 13.165/2015 (Minirreforma Eleitoral de 2015) sob esses mesmos fundamentos, concluiu-se que essa alteração não é suficiente para frear a maximização da relação entre dinheiro e partidos políticos que se traduz numa distorção no âmbito da democracia representativa. Isso porque o papel do poder econômico é fundamental na política. No Brasil, os partidos políticos detêm o monopólio da representação, dessa feita, ensejam recursos, não poucos, para divulgar seu programa, para se fortalecerem e para conquistarem os eleitores.

Concluiu-se também que a diferença existente entre direito de voto e direito de influência justifica a participação das empresas no financiamento das campanhas eleitorais. Pessoa jurídica não vota, é certo, pois empresa não é cidadã, mas pessoas jurídicas têm interesses e, por isso, devem poder exercer seu direito de influência, apoiando, inclusive financeiramente, o candidato/partido que defenda ideias e programas que as beneficiem.

Destarte, concluiu-se que devem ser criados mecanismos de regulação do poder econômico na política: restringi-lo não, mas reduzi-lo sim. As campanhas necessitam ser barateadas, e os limites aos gastos e às doações precisam ser estabelecidos com razoabilidade, com vistas a reduzir a dependência de candidatos e partidos de financiadores isolados. 
Viu-se que o mais importante mesmo é cuidar para que a legislação que instituir tais mecanismos de controle seja observada com rigor. Não há fórmulas universais que garantam o sucesso quando se cuida da regulação do dinheiro na política, mas o que mais importa é divulgar, de forma completa e oportuna, a origem e o destino dos fundos que a financiam, fortalecendo a transparência dos gastos dos partidos políticos como forma de inibir a troca de favores entre doadores e beneficiados. Isso se mostra mais importante do que estabelecer limites e restrições cujo controle e aplicação sejam difíceis de atingir. É necessário que o cidadão possa exercer o voto informado, é necessário que ele saiba quem está por trás de cada candidato, para que possa avaliar suas reais intenções e de seu partido.

Por fim, concluiu-se que a divulgação da origem e do destino dos fundos que financiam as campanhas eleitorais também é útil para incentivar que cada partido venha a controlar os outros, pois isso estimula o ajuste de suas condutas aos parâmetros legais e às exigências da opinião pública.

\section{Referências}

ARAGÃO, Murilo de. Reforma política: o debate inadiável. Rio de Janeiro: Civilização Brasileira, 2014.

BENITES, Afonso. STF decreta o fim das doações de empresas para campanhas eleitorais. E1 País. 17 set. 2015. Disponível em: < http://brasil.elpais.com/ brasil/2015/09/17/politica/1442521595_941009.html>. Acesso em: 20 out. 2015.

BRASIL. Lei n⿳⺈ 9.096, de 19 de setembro de 1995. Dispõe sobre partidos políticos, regulamenta os arts. 17 e 14, S 3o inciso V, da Constituição Federal. Disponível em: < http://www.planalto.gov.br/ccivil_03/LEIS/L9096.htm>. Acesso em: 29 set. 2015.

Lei $\mathbf{n}^{\mathbf{0}} \mathbf{9 . 5 0 4}$, de 30 de setembro de 1997. Estabelece normas para as eleições. Disponível em: <http://www.planalto.gov.br/ccivil_03/LEIS/L9504. htm>. Acesso em: 22 set. 2015.

Mensagem no 358, de 29 de set. de 2015. Disponível em: <http:/ / www.planalto.gov.br/ccivil_03/_ato2015-2018/2015/Msg/VEP-358.htm>. Acesso em: 10 out. 2015. 
COÊLHO, Marcus Vinicius Furtado. Para maioria da população, financiamento privado estimula corrupção. Boletim de Notícias ConJur, 6 jul. 2015. Disponível em: <http://www.conjur.com.br/2015-jul-06/maioria-populacao-financiamento-privado-estimula-corrupcao>. Acesso em: 10 set. 2015.

FALCÃO, Daniel; SANTANO, Ana Cláudia. Financiamento da política no Brasil: novas perspectivas? Disponível em: <http://www.osconstitucionalistas.com.br/financiamento-da-politica-no-brasil-novas-perspectivas Financiamento da política no Brasil: novas perspectivas?>. Acesso em: 1 out. 2016.

FERREIRA FILHO, Manoel Gonçalves. Democracia, eleições e partidos. In: BARRETO, Ricardo de Oliveira Paes; AGRA, Walber de Moura. (Coord.) Prismas do direito eleitoral: 80 anos do Tribunal Eleitoral de Pernambuco. Op. Cit. p. 117-118.

FUX, Luiz. Ação Direta de Inconstitucionalidade 4.650, Distrito Federal, 11 dez. 2013. p. 26. Disponível em: < http://www.stf.jus.br/arquivo/cms/noticiaNoticiaStf/anexo/ADI4650relator.pdf>. Acesso em: 20 out. 2015.

GALLI, Marcelo. Supremo declara inconstitucionalidade de financiamento eleitoral por empresas. Revista Consultor Jurídico, 17 set. 2015. Disponível em: <http://www.conjur.com.br/2015-set-17/financiamento-eleitoral-empresas-inconstitucional-decide-stf $>$. Acesso em: 2 out. 2015.

GOMES, José Jairo. Direito eleitoral. 5. ed. rev. Belo Horizonte: Del Rey, 2010, p. 268.

GUEDES, Néviton. Empresas têm direito de contribuir para as campanhas eleitorais. Revista Consultor Jurídico, 28 jul. 2015. Disponível em: <http:// www.conjur.com.br/2015-jul-28/constituicao-poder-empresas-direito-contribuir-campanhas-eleitorais>. Acesso em: 11 set. 2015.

. Empresas e o direito de participar do debate político-eleitoral. Revista Brasileira de Direito Eleitoral - RBDE, Belo Horizonte, ano 6, $\mathrm{n}^{\circ}$ 10, p. 167-173, jan./jun. 2014b.

KANAAN, Alice. Financiamento público, privado e misto frente à reforma política eleitoral que propõe o financiamento público exclusivo. In: RAMOS, André de Carvalho (Coord.) Temas do direito eleitoral no século XXI. Brasilia: Escola Superior do Ministério Público da União, 2012. Disponível em: $<$ http://escola.mpu.mp.br/linha-editorial/outras-publicacoes/VERSaO_DEFINITIVA_TEMAS\%20DE\%20DIREITO $\% 20$ ELEITORAL $\% 20 N O \% 20$ SECULO \%20XXI\%20sem\%20marcas.pdf>. Acesso em: 10 set. 2015. 
MENDES, Gilmar. Ação Direta de Inconstitucionalidade 4.650, Distrito Federal. Disponível em: < http://s.conjur.com.br/dl/voto-gilmar-mendes. pdf>. Acesso em: 2 out. 2015.

NEISSER, Fernando Gaspar. Doações de empresas e política. Disponível em: <http://cartamaior.com.br/?/Editoria/Principios-Fundamentais/Doacoes-de-empresas-e-politica/40/29775 >. Acesso em: 12 mar. 2015.

O ESTADO DE S. PAULO. Campanhas gastaram R $\$ 5$ bilhões em 2014. 1 dez. 2014. Disponível em: < http://politica.estadao.com.br/noticias/geral,campanhas-gastaram-r-5-bilhoes-em-2014-imp-,1600362\#>. Acesso em: 13 set. 2015.

OHMAN, Magnus. Entendendo o sistema de financiamento político. In: FAGUERA, E.; JONES, S.; OHMAN, M. (Org.) Financiamento de partidos políticos e campanhas eleitorais: um manual sobre financiamento político. Rio de Janeiro: FGV Editora, 2015.

PIRONI, Cristiane Rachel. Igualdade política e financiamento de campanhas eleitorais. 2008. 179 f. Dissertação de Mestrado - Faculdade de Filosofia, Letras e Ciências Humanas, USP, São Paulo, 2009. Disponível em: $<$ www.teses.usp.br/teses/disponiveis/.../CRISTIANE_RACHEL_PIRONI. pdf>. Acesso em: 19 set. 2015.

PORTAL BRASIL. Dilma sanciona reforma política com vetos a financiamento empresarial e voto impresso. 30 set. 2015. Disponível em: <http:// www.brasil.gov.br/governo/2015/09/dilma-sanciona-reforma-politica-com-vetos-a-financiamento-empresarial-e-voto-impresso $>$. Acesso em: 2 out. 2015.

REVISTA CONSULTOR JURÍDICO. Plenário do Senado proíbe financiamento de empresas para campanhas eleitorais. 2 set. 2015a. Disponível em: $<$ http://www.conjur.com.br/2015-set-02/ senado-proibe-financiamento-empresas-campanhas-eleitorais $>$. Acesso em: 25 set. 2015.

. Câmara aprova financiamento eleitoral por empresas e rejeita alterações do Senado. 10 set. 2015b. Disponível em: < http://www.conjur. com.br/2015-set-10/camara-aprova-novamente-doacao-eleitoral-empresas $>$. Acesso em: 25 set. 2015.

RIAL, Juan. O dinheiro e as organizações políticas: regulações e realidade na América Latina. Cadernos Adenauer VI, no 2, 2005, p. 103-104. Disponível em: <http://www.kas.de/wf/doc/9796-1442-5-30.pdf>. Acesso em: 20 set. 2015. 
RUBIO, Delia Ferreira. Financiamento de partidos e campanhas. Fundos públicos versus fundos privados. Novos Estudos - CEBRAP, São Paulo, n.73, nov. 2005. Disponível em: < http://www.scielo.br/scielo.php?pi$\mathrm{d}=$ S0101-33002005000300001\&script=sci_arttext $>$. Acesso em: 1 out. 2015.

SAMUELS, David. Financiamento de campanha e eleições no Brasil: o que podemos aprender com o 'caixa um' e propostas de reforma. In: BENEVIDES, M.V. (Org.). Reforma política e cidadania. São Paulo: Fundação Perseu Abramo, 2003, p. 264-265. Disponível em: <http://escola.mpu.mp.br/ linha-editorial/outras-publicacoes/VERSaO_DEFINITIVA_TEMAS $\% 20$ DE \%20DIREITO \%20ELEITORAL \%20NO \%20SECULO $\% 20 X X I \% 20$ sem\%20marcas.pdf>. Acesso em: 12 set. 2015.

SANTANO, Ana Cláudia. O financiamento da política: Teoria geral e experiências no direito comparado. Curitiba: Íthala, 2014.

- O financiamento público da política dentro da reforma política brasileira: um elemento para o desenvolvimento e consolidação da democracia? In: VICTOR, Sérgio Antônio Ferreira Victor; LONGO, Ana Carolina Figueiró (Org.). Direitos políticos, cidadania e sistemas eleitorais. Brasília: Instituto Brasileiro de Direito público, 2015. p. 66. Disponível em: < http:/ /www.idp. edu.br/publicacoes/portal-de-ebooks/2831-2015-07-01-19-49-19>. Acesso em: 23 out. 2015.

- O financiamento público da política dentro da Reforma Política Brasileira: Um elemento para o desenvolvimento e consolidação da democracia? Revista Direitos Políticos, Cidadania e Sistemas Eleitorais, Brasilia, Instituto Brasiliense de Direito Público, 2015.

SPECK, Bruno W. Reagir a escândalos ou perseguir ideais? A regulação do financiamento político no Brasil. Konder Adenauer Stiftung, p. 123-159, 2015a. Disponível em: <http://www.kas.de/wf/doc/9795-1442-5-30.pdf>. Acesso em: 13 out. 2015.

. O financiamento político e a corrupção no Brasil. 2015b. Disponível em: <https://www.academia.edu/3556070/Bruno_Wilhelm_Speck_O_financiamento_pol $\% \mathrm{C} 3 \% \mathrm{AD}$ tico_e_a_corrup $\% \mathrm{C} 3 \% \mathrm{~A} 7 \% \mathrm{C} 3 \% \mathrm{~A} 3 \mathrm{O}$ _no_Brasil $>$. Acesso em: 2 out. 2015.

STRECK, Lenio Luiz. O realismo ou "quando tudo pode ser inconstitucional. 2014. Disponível em: < http://www.conjur.com.br/2014-jan-02/senso-incomum-realismo-ou-quando-tudo-inconstitucional>. Acesso em: 12 mar. 2015. 


\section{SUPREMO TRIBUNAL FEDERAL. Ação direta de inconstituciona-} lidade (Med. Liminar) - 4650. Brasília, 2015a. Disponível em: <http:// www.stf.jus.br/portal/peticaoInicial/verPeticaoInicial.asp?base $=\mathrm{A}-$ DIN\&s1 $=4650 \&$ processo $=4650>$. Acesso em: 29 set. 2015.

STF conclui julgamento sobre financiamento de campanhas eleitorais. Notícias STF, 17 set. 2015b.

TELES FILHO, Eliardo. Financiamento de campanha: confusão entre direito de voto e influência. Observatório Constitucional, 27 dez. 2014. Disponível em: < http://www.conjur.com.br/2014-dez-27/observatorio-constitucional-confusao-entre-direito-voto-influencia $>$. $>$. Acesso em: 10 out. 2015.

TONIAL, Raíssa; OLIVEIRA, Eltons Somensi de. Os modelos de financiamento de campanha eleitoral e o contexto político-cultural brasileiro. Direito \& Justiça, v. 40, no 1, p. 106-119, jan./jun. 2014. Disponível em: <http:// www.al.sp.gov.br/repositorio/bibliotecaDigital/20545_arquivo.pdf $>$. Acesso em: 1 out. 2015.

TRIBUNAL SUPERIOR ELEITORAL. Série Reforma Eleitoral 2015: regras para mudança de partido ficam mais rígidas. 8 out. 2015. Disponível em: <http://www.tse.jus.br/imprensa/noticias-tse/2015/Outubro/serie-reforma-eleitoral-2015-regras-para-mudanca-de-partido-ficam-mais-rigidas $>$. Acesso em: 20 out. 2015.

ZAVASCKI, Teori. Ação Direta de Inconstitucionalidade 4.650, Distrito Federal, Voto-vista. Disponível em: <http://www.stf.jus.br/arquivo/cms/ noticiaNoticiaStf/anexo/ADI4650TZ.pdf>. Acesso em: 10 out. 2015.

ZOVATTO, Daniel. Financiamento dos partidos e campanhas eleitorais na América Latina: uma análise comparada. Opinião Pública, Campinas, v.11, n.2, out. 2005. Disponível em: < http://www.scielo.br/scielo.php?script=sci_arttext\&pid $=$ S0104-62762005000200002\&lng $=$ pt\&nrm $=$ iso\&tlng $=$ pt $>$. Acesso em: 1 out. 2015.

Luciana Ferreira - Graduada em Direito (UNIVALI). Servidora do Tribunal Regional Eleitoral de Santa Catarina.

Luiz Magno Pinto Bastos Junior - Advogado publicista. Pós-Doutor em Direitos Humanos (Universidade McGill, Canadá). Mestre e Doutor em Direito Público (UFSC). Professor do Programa de Pós-Graduação em Ciência Jurídica da UNIVALI e das disciplinas de direito constitucional, direitos humanos e direito eleitoral dos cursos de graduação em Direito da UNIVALI. Membro fundador da Academia Catarinense de Direito Eleitoral e Academia Brasileira de Direito Eleitoral e Político. Membro das Comissões de Direito Eleitoral e de Direito Constitucional da OAB/SC. E-mail: lmagno@mnadvocacia.com.br. 